\title{
The Impact of Foreign Direct Investment (FDI) on Gross Domestic Production (GDP) in Indian Economy
}

\author{
${ }^{*}$ Pratibha S.Gaikwad, Gholamreza Fathipour \\ ${ }^{1}$ Chhatrapati Shivaji College, Satara, Maharashtra, India \\ 2Pune University, Maharashtra, India \\ *pratibhasg11@gmail.com
}

\begin{abstract}
In this study, an attempt has been made to analyze the effects flow of foreign direct investment (FDI) arising from the implementation of liberalization polices (economic reform) on the gross domestic production (GDP) growth in Indian economy using a Cobb-Douglas production function and ARDL method during the period 1990-2008. The empirical results show that in the long run there exists a long-run relationship among the growth of gross domestic production and its major determinants of the labour force, the real capital and the real foreign direct investment. Finding indicates that foreign direct investment has positive effect but small significant on Gross Domestic Production, while the labour force and capital have had the most effect on gross domestic production.
\end{abstract}

Keywords: Gross Domestic Production, trade liberalization, foreign direct investment, ARDL approach, Indian economy

\section{Introduction}

Inflow of capital from abroad in the form of private investment is important for the growth of developing the economy; especially at the initial stage of its economic development. Foreign investment has beneficial effects in terms of encouragement to the development of technology, managerial expertise, exports and higher growth.

FDI in India: India has undergone a paradigm shift owing to its competitive stand in the world. The Indian economy is on a robust growth trajectory and boasts of a stable 8 plus annual growth rate, rising foreign exchange reserves and booming capital markets among others. Looking at the statistics, the macroeconomic situation of the country seems strong and positive- the GDP in the third quarter of 2006-07 grew at an impressive rate of 8.6 percent, the forex reserves stood at US\$193.12 billion (as on February 23, 2007), the Indian Sensex crossed the 14000 mark in the month of December 2006 and the number of registered FIIs in the country has gone up from 823 in December 2005 to a staggering 1000 in December 2006. There is ample reason for India's viability as a destination for foreign investment. In addition to the above-mentioned macroeconomic indicators, higher disposable incomes, emerging middle class, low cost competitive workforce, investment friendly policies and progressive reform process all contribute towards India being an appropriate choice for investors.

Model and Data: The theoretical framework of the study derives from the Cobb-Douglas production function, which is consistent with the specification used in several previous studies (see for example Ramirez (2000), Dutta and Ahmed (2006), Rahimi and Shahabadi (2011)). The link between foreign direct investment and the growth rate of gross domestic production is verified by using an aggregate production function framework. Following us, specify a gross domestic production function for India in the following way:

$$
\mathrm{Y}=\mathrm{f}(\mathrm{L}, \mathrm{K}, \mathrm{FDI})
$$

Where Y is the gross domestic production; K, L, and FDI represent, respectively, labour and capital inputs, and an index of trade liberalization. Based on the availability of time-series data and relevance to the gross domestic production function for India, we use measure of trade liberalization in this paper: the real foreign direct investment (FDI). Consequently, our aggregate (gross domestic production) function becomes: 
RGDP=f (Labourp, Rcapital, Rforiegn Direct Investment)

(2)

Specifying the production function in log-linear form (with an error term, $\mathrm{u}_{\mathrm{t}}$ ), the following equation may be written:

$$
\operatorname{LGDP}_{\mathrm{t}}=\alpha_{0}+\alpha_{1} \text { LLabour }_{\mathbf{t}}+\alpha_{2} \text { LCaptial }_{\mathrm{t}}+\alpha_{3} \text { LFDI }_{\mathrm{t}}+\mu_{\mathrm{t}}
$$

It is expected that the elasticity parameters $\left(\alpha_{1}, \alpha_{2}, \alpha_{3}\right)>0$

Where, LGDP is the natural log of real gross domestic production. L Labour is the natural log of the labour force and Lr capital is the natural log of real gross fixed capital. Lfdi is the natural log of the real foreign direct investment. The sources of the data were time series database of, Ministry of Statistics and Program Implementation, Government of India and the National accounts statistics, central statistics organization, and ministry of planning, government of India and the Report on currency and finance, Reserve Bank of India. Suitable deflators have been used to deflate the time series data. The price index (base on 2000-2001=100)

\section{Methodology}

Economic theories confirm the existence of certain long-term equilibrium relationship between some economic variables. The co-integration test is to find out whether there is a long-term equilibrium relationship between variables. Co-integration is a statistical description of long-term equilibrium relationship between unstable variables, which is also the precondition for making causality regression of variables. This equilibrium indicates that there is not an internal mechanism destroying the equilibrium in an economic system. The most regular method for co-integration test is to use OLS to make co-integration regression of variables. The pioneering work on co-integration analysis was done by Engle and Granger (1987). After this, the researchers like Stock and Watson (1988) and Johansen (1988) tried to extend the work. Johansen (1988) approach provides the number of co-integration equations among the variables. In time series analysis the explanatory variable may influence the dependent variable with a time lag. This often necessitates the inclusion of lags of the explanatory variable in the regression. Furthermore, the dependent variable may be correlated with lags of itself, suggesting that lags of the dependent variable should be included in the regression as well. These considerations motivate the commonly used ARDL (p; q) model. The Auto-Regressive Distributed Lag Method (ARDL) "Bounds test" approach is based on the ordinary least square (OLS) estimation of a conditional unrestricted error correction model (UECM) for cointegration analysis developed by Pesaran et al. (2001). Rahimi and Shahabadi (2011) based on former studies have stated that the ARDL Bounds test approach has several advantages over the Johansen's cointegration method. Firstly, the ARDL efficiently determines the cointegrating relation in small sample cases, whereas Johansen's method requires a large sample for validity. Secondly, Johansen's method requires that variables must be integrated with variables of the same order for the cointegration test, while the ARDL approach can be applied irrespective of whether the regressors are I(1) and I(0) or mutually cointegrated, in which the dependent variable must be I(1). In a regression analysis, there is an important assumption in a classical regression model, that is, the sequence must be stable. If the sequence is unstable, the test will be invalid or the regression will be false. However, for many unstable variables, it cannot be used the classical regression model to make an analysis. Otherwise, it may cause an issue of false regression. If the nature of the stationarity of the data is not clear, then the use of the ARDL Bounds test is appropriate.

Therefore ARDL approach is used to test for the existence of a long run relationship as well as to make an estimation of long and short run coefficients for the study where the trade liberalization variables and dummy can capture both the short run and long run impacts. As it was mentioned, major advantage of the ARDL approach is that it can be applied to studies that have a small sample size. It is well known that the Engle \& Granger $(1987)$ and Johansen $(1988,1995)$ methods of cointegration are not reliable for small sample sizes. Several previous studies, however, have applied the ARDL approach to relatively small sample sizes. Gounder $(1999,2002)$ has used the ARDL methodology to test empirically various growth hypotheses for Fiji using similar sample sizes to that in this study. Rahimi and Shahabadi (2011) have used the ARDL methodology to investigate the effect of trade liberalization on economic growth in Iranian economy using a Cobb-Douglas production function. According to Tang (2003) that has applied the ARDL Bounds test approach to estimate the import demand function for Japan with only 18 annual observations; we apply also the ARDL Bounds test approach with 18 annual observations. Therefore, application of the ARDL Bounds test 
approach is very appropriate. According to Pesaran and Pesaran (1997), the augmented ARDL (p, $\mathrm{q}_{1}, \mathrm{q}_{2}, . ., \mathrm{q}_{\mathrm{k}}$ ) model can be expressed in the following form:

$\mathrm{Dy}_{\mathrm{t}}=\mathrm{c}_{0}+\mathrm{c}_{1} \mathrm{t}+\lambda_{\mathrm{yx}} \mathrm{Z}_{\mathrm{t}-1}+\sum_{\mathrm{i}=1}^{\mathrm{p}-1} \gamma_{\mathrm{i}} \mathrm{Dy}_{\mathrm{t}-\mathrm{i}}+\sum_{\mathrm{i}=1}^{\mathrm{p}-1} \gamma_{\mathrm{i}} \mathrm{DX}_{\mathrm{t}-\mathrm{i}}+\delta_{\mathrm{i}} \mathrm{w}_{\mathrm{t}}+\mathrm{u}_{\mathrm{t}} \quad \mathrm{t}=1, \ldots, \mathrm{n}$

Where $D$ is the first difference operator, $t$ is the trends, the coefficient $Y_{i}$ is expressing the short run dynamics of the model's convergence to equilibrium and $\mathrm{Z}_{\mathrm{t}}=\left(\mathrm{y}_{\mathrm{t}}^{\prime}, \mathrm{x}_{\mathrm{t}}^{\prime}\right)$

From the ARDL it can be derived a dynamic error correction model (ECM) following a simple linear transformation (Banerjee et al., 1993), where the ECM integrates short run dynamics with long run equilibrium without losing long run information (Shrestha \& Chowdhury, 2005). Error correction model (ECM) is useful for short run dynamics with long run equilibrium relationship. On this basis, take the longterm equilibrium relationship of sequences as the error correction term. The error correction term, as an explanatory variable, and other variables that influence short-term fluctuations constitute an error correction model. There are several techniques for ECM in the existing literature. In this study we apply sophisticated econometrics technique like Error Correction Model (ECM), which is used for empirical investigation of the determinants of gross domestic production (GDP) in short and long run. The ECM is more useful in multivariate framework. Here, our basic presumption is that GDP is endogenous and all other variables in the long run relationship are exogenous. According to Pesaran et al. (2001) and Bahmani-Oskooee, for estimation, the economic growth Eq. (1) can be expressed in the UECM version of the ARDL model as follows:

$\mathrm{D}(\mathrm{LGDP})_{\mathrm{t}}=\beta_{0}+\sum_{i=1}^{n} \beta_{1 i} \mathrm{D}(\text { LLabour })_{t-i}+\sum_{i=1}^{n} \beta_{2 i} \mathrm{D}(\text { LCapital })_{t-i}+\sum_{i=1}^{n} \beta_{3 i} \mathrm{D}(\mathrm{LFDI})_{t-i}+\beta_{4 i} \mathrm{ECT}_{t-i}+\varepsilon_{\mathrm{t}}$

This leads to the specification of a general ECM of the industrial production function of the following form: Where $\mathrm{ECT}_{\mathrm{t}-\mathrm{i}}=$ error-correction term lagged one period.

\section{Empirical Results}

This study tests the presence of co-integrating relationship between GDP and FDI using the Pesaran et al. (2001) Auto-Regressive Distributed Lag Method (ARDL).The procedures of the ARDL Bounds test approach include three steps. The first step is to determine the existence of a long run co integrating relationship among the variables in the equation. The long run level relationship between the variables is determined using the Wald-coefficient test or T-test. According to T-test, if the estimated T-statistic appears larger than the critical value, then the null hypothesis of no co integration is rejected, which suggests that the variables included in the model are co integrated (Banerjee, et al, 1998). The second step is to estimate the elasticities of the long run relationship and determine their values. Finally in the third step, we calculate the short run elasticities from the coefficients of the first differenced variables of the ARDL model. The coefficients of the first differenced variables in the estimated UECM represent short run elasticities (Tang, 2003). To ascertain the goodness of fit of the ARDL model, relevant diagnostic tests and stability tests are conducted. The diagnostic tests examine the normality, serial correlation, ARCH and heteroscedasticity associated with the model. The structural stability test is conducted by employing the CUSUM and CUSUM of Squares tests. Since we use 18 annual observations, we choose 1 as the maximum lag length in the ARDL model. So following Banerjee et al. (1998) to determine the long-run relationship among the variables of interest, we use the ttest. Based on the results in table 1, the calculated value of the t-test is -5.51 , which is more than the critical value -4.92 (at 99\% significance level) tabulated by Banerjee et al. (1998), so the presence of the long-run relationship is confirmed.

The examination of data on the table 1 shows that labour and capital variables respectively such as mainly factors on production have had more influence on the GDP variable. The estimated coefficient of labour and capital are positively and statistically significant at $5 \%$ level. The coefficient variables of labour and capital are 0.43 and 0.23 per cent respectively. In other word a one percentage point rise in labour and capital growth would cause GDP to growth by approximately 0.43 and 0.23 per cent respectively percentage point of GDP per annum. The other variable as the foreign domestic investment have positive effect on the GDP growth. One percent increase in the foreign direct investment has led to increase in the GDP growth by 0.015 
percent of course with one lag. It indicate that the Indian activity on economy (trade liberalization and industrial policies) especially FDI flow have been an effective factor on economic in India.

Table 1: Autoregressive Distributed Lag Estimates selected based on SBC

\begin{tabular}{cclc}
\hline Regressor & Coefficient & Standard Error & T-Ratio [Prob] \\
\hline GDP $(-1)$ & 0.56617 & 0.078794 & $7.1854[0.000]$ \\
L & 0.43558 & 0.16567 & $2.6292[0.021]$ \\
K & 0.23678 & 0.052780 & $4.4862[0.001]$ \\
FDI $(-1)$ & 0.015707 & 0.0068818 & $2.2824[0.040]$ \\
C & 0.47662 & 0.50788 & $0.93844[0.365]$ \\
R-Squared $=0.998$ & R-Bar-Squared $=0.997 \quad$ DW $=1.9525$ & $\mathrm{~F}(4,13)=1987.8[0.000]$ \\
\hline
\end{tabular}

Next we estimate the long-run coefficients of the ARDL model. One of the more important issues in applying ARDL is choosing the order of the distributed lag functions. Although Pesaran and Smith (1998) argue that the Schwarz Bayesian Criterion (SBC) should be used in preference to other model specification criteria because it often has more parsimonious specifications. The optimal number of lags for each of the variables is shown as ARDL $(1,0,0)$. Table 2 shows the long-run coefficients of the variables under investigation. As it expected in the long run one percent increases in foreign direct investment leads to 0.036 per cent increase in the GDP growth by one lag year. This indicate that the foreign direct investment have a few statistically significant effect for long run on GDP growth in Indian economy.

Table 2: Estimated Long-run Coefficients using the ARDL Approach

\begin{tabular}{cccc}
\hline Regressor & Coefficient & Standard Error & T-Ratio [Prob] \\
\hline L & 1.0040 & 0.32756 & $3.0653[0.009]$ \\
K & 0.54579 & 0.086344 & $6.3211[0.000]$ \\
FDI $(-1)$ & 0.036206 & 0.015081 & $2.4007[0.032]$ \\
C & 1.0986 & 1.1424 & $0.96167[0.354]$ \\
\hline
\end{tabular}

After estimating the long-term coefficients, we obtain the error correction version of the ARDL model. Table 3 reports the short-run coefficient estimates obtained from the ECM version of the ARDL model. The error correction term indicates the speed of adjustment restoring the equilibrium in the dynamic model. Error correction coefficient (ECM) shows that in each period, how much percentage of short-term imbalances in the industrial added value is adjusted to achieve long-term equilibrium. The ECM coefficient shows how quickly/slowly the relationship returns to its equilibrium path, and it should have a statistically significant coefficient with a negative sign. Banerjee et al. (1998), states that a highly significant error correction term is further proof of the existence of a stable long term relationship. As can be seen in table 3 the expected negative sign of the ECM is highly significant. The estimated coefficient of the ECMt(-1) is equal to -0.43 , suggesting that deviation from the long-term inflation path is corrected by around 0.43 percent over the following year. This means that the adjustment takes place very quickly.

Table 3: Short-run Error Correction Model (ECM), (Dependent Variable: dlva)

\begin{tabular}{cccc}
\hline Regressor & Coefficient & Standard Error & T-Ratio [Prob] \\
\hline $\mathrm{dL}$ & 0.43558 & 0.16567 & $2.6292[0.021]$ \\
$\mathrm{dK}$ & 0.23678 & 0.052780 & $4.4862[0.001]$ \\
$\mathrm{dFDI}(-1)$ & 0.015707 & 0.0068818 & $2.2824[0.040]$ \\
$\mathrm{dC}$ & 0.47662 & 0.50788 & $0.93844[0.365]$ \\
ecm $(-1)$ & -0.43383 & 0.078794 & $-5.5058[0.000]$ \\
R-Squared $=0.75434$ & R-Bar-Squared $=0.67875$ & $\mathrm{DW}=1.9525$ & $\mathrm{~F}(4,13)=9.9795[.001]$ \\
\hline
\end{tabular}

The coefficient of determination, $\mathrm{R}^{2}$, is reasonably high, implying that approximately $75 \%$ of total variation in GDP in India is explained by the specified macroeconomic determinants of GDP function. The Durbin-Watson statistic being close to 2 indicates that residuals are uncorrelated with their lagged values, that is, there is no first-order serial correlation problem among the residuals. Diagnostic tests for serial correlation, functional 
form, normality, heteroscedasticity, and structural stability of the model in table 4 shows that there is no evidence of autocorrelation and the model passes all of the reported diagnostic tests.

Table 4: The results of Diagnostic tests

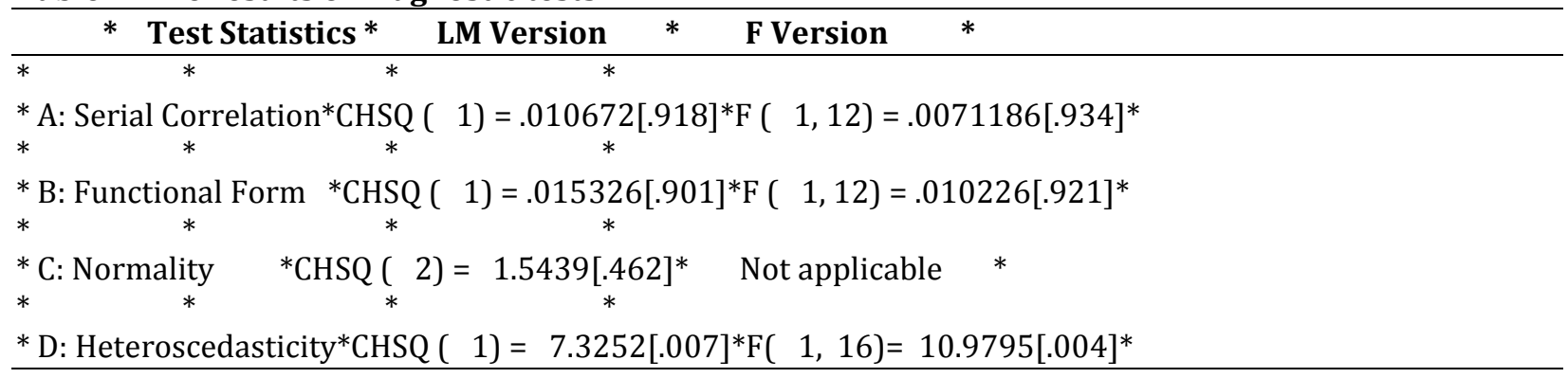

A: Lagrange multiplier test of residual serial correlation

B: Ramsey's RESET test using the square of the fitted values

C: Based on a test of skewness and kurtosis of residuals

D: Based on the regression of squared residuals on squared fitted values

Finally, the cumulative sum of recursive residuals (CUSUM) and the CUSUM of squares (CUSUMSQ) tests were applied to test for parameter constancy. Figure 1 plots the CUSUM and CUSUM of squares statistics for Eq. (4). The results clearly indicate the absence of any instability of the coefficients during the investigated period because the plots of the two statistics are confined within the $5 \%$ critical bounds pertaining to the parameter stability.

Figure (1): Plots of CUSUM and CUSUMQ statistics for coefficients Stability Tests
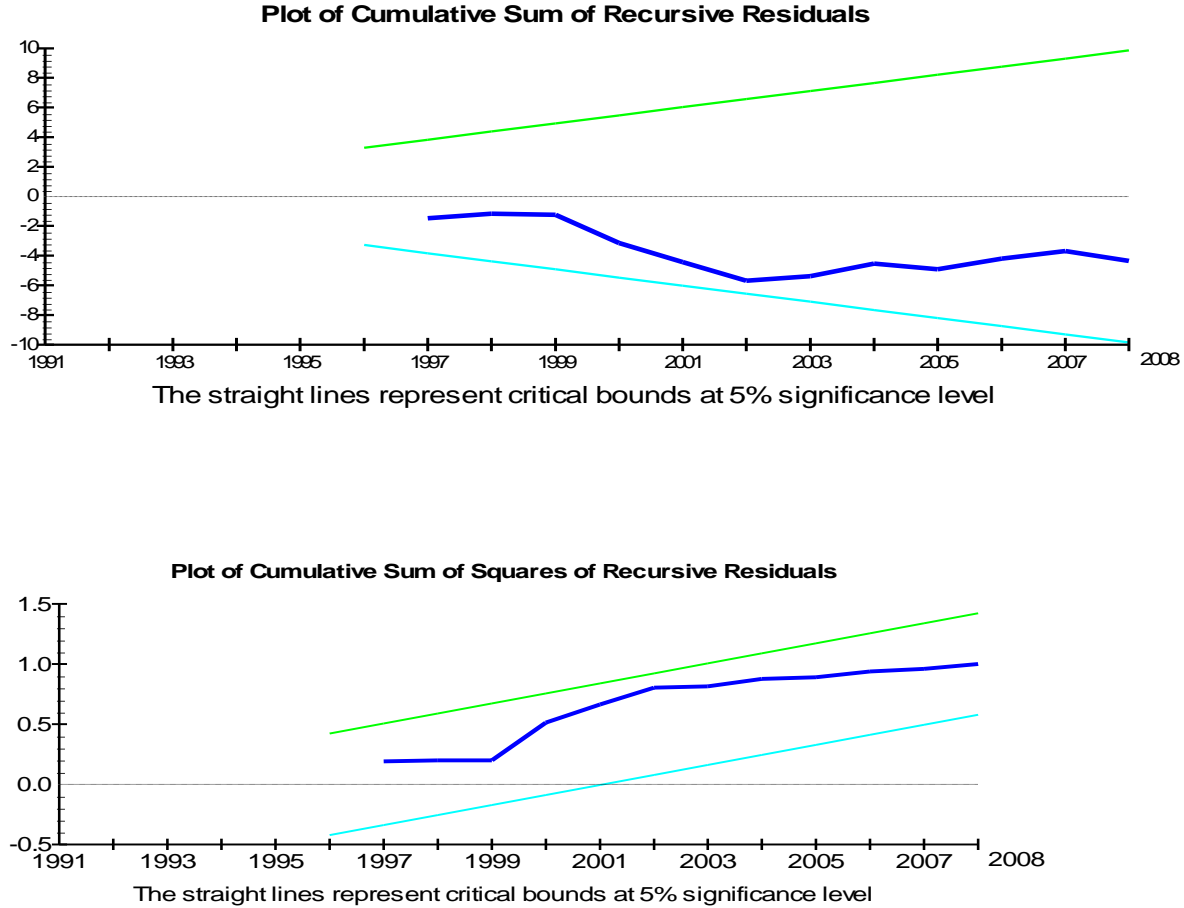


\section{Conclusion}

This study has estimated and analyzed the impacts of foreign direct investment on the GDP growth in Indian economy by use of a Cobb-Douglas production function and the ARDL 'Bounds test' approach with annual time series data from 1990 to 2008,. It was found that the variables in the GDP growth function are co integrated. The labour and capital variables (with most effect), the significantly influence on the GDP growth with consistent signs. These indicate that the labour and capital have a substantial or statistically significant effect for long run on the GDP in Indian economy. The foreign direct investment have a positive but few significant effect on GDP, it indicate that the Indian activity on economy in trade liberalization and foreign direct investment have been an effective factor on GDP in India but with weak effect. Error correction coefficient (ECM) shows that in each period, how much percentage of short-term imbalances in the industrial added value is adjusted to achieve long-term equilibrium. The error correction coefficient, estimated at -0.43 is statistically significant at the 1 per cent level, has the correct sign, and suggests a rapid speed of convergence to equilibrium. On the whole, from the above findings and analysis, it is apparent that India has been following trade liberalization and industrial policies to expand foreign direct investment and reinforce trade via foreign direct investment hence improve the GDP growth.

\section{Reference}

Bahmani-Oskooee, M. \& Nasir, A. (2004). ARDL approach to test the productivity bias hypothesis. Review of Development Economics, 8(3), 483-488.

Banerjee, A., Dolado, J. \& Mestre, R. (1998). Error-correction mechanism tests for cointegration in a single equation framework. Journal of Time Series Analysis, 19, 267-283.

Banerjee, A., Dolado, J., Galbraith, J. W. \& Hendry, D. F. (1993). Co-integration, Error Correction and the Econometric Analysis of Non-Stationary Data, Oxford: Oxford University Press.

Dutta, D. \& Ahmed, N. (2006). Trade liberalization and industrial growth in Pakistan: a cointegration analysis. Applied Economics, Taylor and Francis Journals, 36(13), 1421-1429.

Engle, R. F. \& Granger, C. W. J. (1987). Cointegration and error correction representation: estimation and testing. Econometrica, 55, 251-276.

Gounder, R. (1999). The political economy of development: empirical results from Fiji. Economic Analysis and Policy, 29, 133-150.

Gounder, R. (2002). Political and economic freedom, fiscal policy and growth nexus: some empirical results for Fiji. Contemporary Economic Policy, 20, 234-245.

Johansen, S. (1988). Statistical analysis of cointegrating vectors. Journal of Economic Dynamics and Control, 12, 231-254.

Johansen, S. (1995). Likelihood-based Inference in Cointegrated Vector Autoregressive Models, Oxford: Oxford University Press .

Pesaran, M. H. \& Pesaran, B. (1997).Working with Microfit 4.0: Interactive Econometric Analysis ,0xford: Oxford University Press.

Pesaran, M. H. \& Smith, R. (1998). Structural analysis of cointegration VARS. Journal of Economic Surveys, 12(5), 471-505.

Pesaran, M. H., Shin, Y. \& Smith, R. J. (2001). Bound testing approaches to the analysis of level relationships. Journal of Applied Econometrics, 16, 289-326.

Rahimi, M. \& Shahabadi, A. (2011). Trade Liberalization and Economic Growth in Iranian Economy. Available at SSRN: http://ssrn.com/abstract=1976299 or http://dx.doi.org/10.2139/ssrn.1976299

Ramirez, M. (2000). Foreign direct investment in Mexico: a cointegration analysis. Journal of development Studies, 37, 138-162.

Shrestha, M. B. \& Chowdhury, K. (2005). ARDL modeling approach to testing the financial liberalization hypothesis, Economics Working Paper Series 15

Stock, H. J. \& Watson, W. M. (1988). Variable trends in economic time-series. Journal of Economic Perspectives, $2(3), 147-174$.

Tang, T. C. (2003). Japanese aggregate import demand function: Reassessment from bound testing approach. Japan and the World Economy, 15(4), 419-436. 